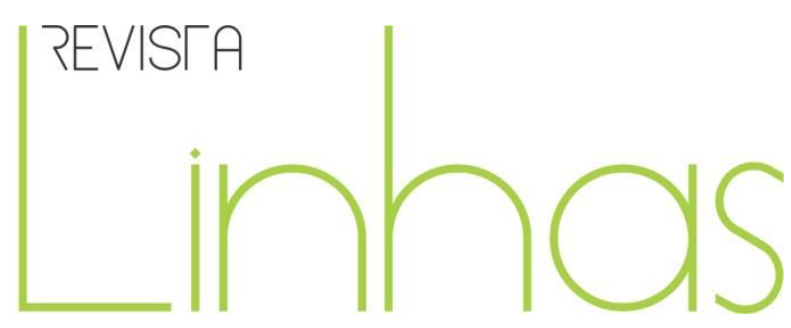

\title{
Docência, reformas curriculares e formação docente no Ensino Médio
}

\begin{abstract}
Resumo
O presente artigo apresenta alguns elementos defendidos como basilares para a discussão sobre a formação docente em suas múltiplas dimensões, a partir da análise dos processos de reforma educacional ocorridos no Ensino Médio no Brasil, com a Lei $n^{\circ}$ 9.394/1996 e a Lei $n^{\circ}$ 13.415/2017. No texto estão localizadas mudanças curriculares introduzidas por essas reformas, ao mesmo tempo em que também discute as suas implicações nos processos da organização da escola, do trabalho, da vida e formação docente. São apresentados depoimentos de docentes que vivenciaram as reformas resultantes da LDB de 1996 e análises produzidas sobre a Lei $n^{\circ}$ 13.415/2017. Problematiza a discussão dessas reformas, os processos de mudanças curriculares por elas introduzidos e conclui situando os desafios e perspectivas para a formação de professores/as dessa etapa da Educação Básica, em especial para a formação continuada.
\end{abstract}

Palavras-chave: Processos de Autoformação: Formação Inicial e Continuada de Professores. Ensino Médio. Educação e Estado. Currículos.
Elenita Pinheiro de Queiroz Silva

Universidade Federal de Uberlândia

- UFU - Uberlândia/MG - Brasil elenita@ufu.br

Marcelo Soares Pereira da Silva

Universidade Federal de Uberlândia

- UFU - Uberlândia/MG - Brasil marcelospsilva@hotmail.com

\section{Para citar este artigo:}

SILVA, Elenita Pinheiro de Queiroz; SILVA, Marcelo Soares Pereira da. Docência, reformas curriculares e formação docente no Ensino Médio. Revista Linhas. Florianópolis, v. 20, n. 43, p. 161-183, maio/ago. 2019. 


\section{Teaching, curricular reforms and teacher training in middle school}

This article presents some elements defended as basic for the discussion about teacher education, in its multiple dimensions based on the analysis of the educational reform processes that occurred during High School in Brazil, with law number 9,394/1996 and law number $13.415 / 2017$. Within the text, there are located curricular changes introduced by these reforms, while also discussing the implications of the same in the processes of school organization, work, life, and teacher training. We present testimonies of teachers who have experienced the reforms resulting from the LDB of 1996 and analyzes produced on law number 13.415/2017. It problematizes the discussion of these reforms, the processes of curricular changes that they introduce, and concludes by situating the challenges and perspectives for teacher training at this stage of basic education, especially for continuing education.

Keywords: Processes of Self-Training: Initial and Continuing Teacher Training. High School. Education and State. Curriculum. 


\section{Apresentação}

Falar da formação docente é articular os vários espaços e as múltiplas dimensões em que esta se processa, se instala e se constitui, e a escola é um desses espaços que espelha tal articulação. Esta instituição, em sua gênese, carrega a sistematização do conhecimento como princípio; nasce no século VIII ou VII a.C., na Grécia, e teria a finalidade de organizar uma série de fenômenos e, sobretudo, "dar princípio a algo que deveria tornar-se firme e estável” (ESPÓSITO, 1995, p. 116-117).

Quando a escola surge na sociedade grega, ela se firma para dar garantia da unidade e manifesta-se enquanto norma, modelo, padrão de conduta e de ação, cria sentido para estabelecer base, medida para a realização ou avaliação de alguma coisa. A instituição Escola destina-se a reunir, a legislar, a manter, a se contrapor ou desfazer, a fazer síntese. Ela produz-se nessa tensão, em movimento.

Ao longo de nossa experiência acadêmica, particularmente no exercício da pesquisa, ao apresentarmos a escola, consideramo-la em toda a sua complexidade: suas normas, regulamentos, lugar onde está situada geográfica, cultural e politicamente, e, também, nos e pelos modos de vida nela existentes. Tornou-se, em nossa experiência, importante olhar para essa instituição, para a função de sua capacidade de "dar forma e organizar" como parte de sua dinâmica. Isso tem significado

Vê-la na sua essência (o tempo do ser da escola), mas também na sua existência (em tempo de sociedade), como algo que se dá ao homem, como ser situado no tempo e no espaço, sofrendo a facticidade de ser ao mundo de forma perspectival, na tensão e no movimento, numa dialética sem síntese. (ESPÓSITO, 1995, p. 119)

Temos, assim, pensado a escola como lugar de encontro entre mulheres, homens, meninos e meninas. Lugar de estabelecimento de relações sociais de toda ordem. Essa via de entendimento nos conduziu a desconstruir a ideia de mesmice que muitas vezes, no cotidiano, inclusive profissionais da educação, têm associado a essa instituição. Quando entendemos que ela se constitui, é constituída e constitutiva de relações sociais, de poder e de sabres, então, como pensá-la como “mesma”? Como pensá-la idêntica? Como buscála, sem pensar e experienciar a complexidade e teia na qual está imersa, da qual é parte? 
Cabe salientar que essa mesmice estaria retratada nas coisas que, como profissionais da educação, dizemos serem próprias de qualquer escola, são próprias da relação professor(a)/aluno(a)/conhecimento atrelada a uma visão de mundo que estrutura-se a partir do princípio de homogeneidade em detrimento do princípio da heterogeneidade; pelo princípio da universalidade em detrimento do princípio da multiplicidade.

Para Espósito (1995, p. 119), a instituição escola carrega a unidade na multiplicidade: "Como unidade na multiplicidade, e ao se manter nessa união consistente e estável, a escola se presentifica como entidade, mantendo uma estrutura interior nãofluida e que funciona como fator unificante". Essa não fluidez vai sendo reconhecida, também, por aquilo que é normatizado, regulamentado, regimentado tanto no interior do espaço escolar, quanto em outros espaços que essa instituição invade, nos quais é pensada.

No entanto, a ausência de fluidez trazida por Espósito, citada nos parágrafos anteriores deste texto, torna-se paradoxal quando nos damos conta de que, na escola, e, em todos os lugares onde ela é pensada, há tensões, conflitos, disputas, jogos de interesses, de poder, discursos que (de)marcam continuamente os movimentos nela estabelecidos. Tudo isso ganha concretude, por um lado, nos textos oficiais, nas imagens dela produzidas e, por outro, em textos que se constroem, a partir da problematização da produção e dos efeitos sobre os sujeitos, provocados por essas tensões, conflitos, disputas, jogos, imagens, discursos e textos. Desse modo, entram em jogo, para nós que lidamos com o campo da pesquisa e da formação continuada, os modos como vêm sendo operadas a função aluno/a, a função docente, as condições de trabalho, e os modos de sobrevivência dentro e a partir da escola.

Desse modo, em momentos de instalação de outros modelos de organização da educação básica, com alterações do modo de funcionamento e organização dos níveis de ensino, a partir do entendimento de escola que defendemos aqui, não é possível deixar de lado as vidas, e como elas sofrem os efeitos dessas alterações. Isso significa dizer que as mudanças decorrentes e introduzidas pela e nas Leis de Diretrizes e Bases da Educação Nacional carregam um conjunto de alterações nas vidas de professores/as e alunos/as, e, por conseguinte, tais alterações precisam ser discutidas, estudadas, pensadas na 
formação docente quer inicial ou continuada, nas experimentações que produzimos com esses e essas profissionais.

Neste texto, tomaremos dois momentos, em que na história recente do Brasil, isso ocorreu. Com um olhar voltado para o Ensino Médio, o primeiro momento diz respeito às mudanças introduzidas pela Lei 9.394/1996 que define as Diretrizes e Bases da Educação Nacional (LDB Lei n. 9.394/1996). O segundo momento se refere às alterações ocorridas nessa mesma LDB, a partir da aprovação da Lei $n^{0}$ 13.415/2017, que trouxeram novas mudanças na organização do Ensino Médio. E, assim, passamos a expor esses dois momentos com a intencionalidade de apontar para as nossas múltiplas experiências em momentos passado/presente constitutivos de nossa e de outras experiências de formação continuada. Fazer pensar os movimentos da/e na escola, provocados por outros movimentos interessados nessa instituição, como âncora para fazer produzir modos particulares de vida sem com esta se atentar, foi o nosso grande interesse nesta escrita. Movimentar experiências e reflexões, com pontos muitas vezes díspares para, ao final, (re)afirmar as multiplicidades que constituem a função docente e a vida na escola.

\section{A LDB de 1996 e o Ensino Médio}

Quando nos debruçamos sobre a proposição de Ensino Médio, desenhada pela LDB de 1996, já observávamos que ela apontava para uma "formação para o trabalho", como afirmado em seus artigos 35 e 36, ao mesmo tempo em que foi definida essa etapa como a etapa final da educação básica e com caráter de formação geral. A partir dessas referências legais, na segunda metade dos anos 1990 do século passado, assim como ocorrera em outros estados da federação, no estado da Bahia, foram elaboradas e indicadas proposta visando o redirecionamento do Ensino Médio por meio de uma adequação curricular. Desatrelar o Ensino Médio do caráter de formação profissionalizante que caracterizava o antigo $2^{\circ}$ grau, nos termos da Lei $n^{\circ} 5.692 / 1971$, foi uma ação que acionou um conjunto de sujeitos na estrutura dos sistemas de ensino e da própria instituição escolar. Dessa forma, por vezes, o que as escolas que ofertavam o ensino de $2^{\circ}$ grau viveram, em todo país, foi um processo de reestruturação de seus currículos, de redirecionamento na linguagem oficial, especialmente a partir de 1997-1998 com a divulgação, pelo Ministério da Educação, dos chamados Parâmetros Curriculares 
Nacionais (PCN) e com a aprovação, pelo Conselho Nacional de Educação, das Diretrizes Curriculares Nacionais para o Ensino Médio. Com efeito, a instauração de uma nova linguagem carrega consigo a instauração de práticas, exercício de poder, de modos de viver a escola e o trabalho que nela se realiza e pelo qual ela é, social e politicamente, responsável. Assim, vimos ser apresentadas mudanças que alteraram a estrutura da escola, a vida de professoras e de professores, dos estudantes, enfim, de toda comunidade escolar.

A esse respeito, temos registrado a experiência de pesquisa realizada em $2002^{1} \mathrm{em}$ uma escola de $2^{\circ}$ grau com oferta de cursos profissionalizantes, em pleno processo de instauração das mudanças ocorridas naquele momento histórico. Naquela escola, o sentimento de impotência foi revelado por professoras e professores diante das proposições trazidas pela reformulação curricular para o Ensino Médio, em momentos de formação continuada no interior da escola. E essas alterações não afetaram as pessoas apenas no sentido da substituição de oferta de cursos profissionalizantes por cursos de formação geral. Foi mais do que isso; associada a essa substituição, veio uma proposição de condutas, saberes, valores, que deixaram os/as professores/as atônitos/as diante das "novas" exigências.

São termos, metodologias, práticas, atitudes cobradas, sem que eles/as tivessem, ao menos, tempo para se aproximar do que estava acontecendo. É o conflito e, ao mesmo tempo, confronto entre a formação que eles/as tinham e a formação necessária para condução e implementação do que chegava à escola de modo impositivo.

[...] nós saímos no final do ano de férias, e, quando chegamos no início do outro ano, já estava aquela coisa ali. Tinha que trabalhar com interdisciplinaridade, com competências, com habilidades... a gente ficou atordoado. Tinha disciplinas com mudança de carga horária, tinha uma coisa chamada PEI... muita coisa pra gente dar conta, sem nem saber do que se tratava. (M2, 2001, entrevista oral IV) ${ }^{2}$

\footnotetext{
${ }^{1}$ Para este estudo, foram entrevistadas quinze professoras em atividade de sala de aula. Dessas, duas não fizeram curso de licenciatura, as demais concluíram sua graduação na Universidade Estadual de Feira de Santana-Bahia. Apenas uma fez o Curso de Licenciatura em Pedagogia. Essas entrevistas compõem a dissertação de Mestrado defendida por Elenita Pinheiro de Queiroz Silva, no Programa de Pós-Graduação em Educação da Universidade Federal da Bahia.

${ }^{2}$ Os símbolos $M 2, M, M 1, M C$ são utilizados para identificar a fala das professoras entrevistadas ao longo do texto.
} 
Questionada, ainda, se não teria havido uma discussão mais ampla na escola, com informações, propostas de discussão, essa mesma professora complementa: “Aqui?! Olha se chegou foi lá por cima, em nível de direção; para a gente, não!"

Essas afirmações representaram um consenso entre um número expressivo de professoras/es de escolas públicas de Ensino Médio da cidade, à época. Tanto nessa, quanto em outras escolas, foi comum ouvir a preocupação com as terminologias trazidas. E, por vezes, o ponto central das preocupações era em torno de: "como dar conta disso?" Nunca se perguntava “por que temos fazer isso ou aquilo?" "Por que esse currículo e não outro?".

As professoras relataram, ainda, a angústia de ter que, repentinamente, reorganizar toda a vida profissional, suas bases, suas referências, suas práticas, pois as alterações no ensino de $2^{\circ}$ grau provocaram instabilidades no trabalho escolar e apresentaram novas exigências para a escola e seus profissionais. As mudanças introduzidas na organização do Ensino Médio no Brasil como um todo, e na Bahia em específico, trouxeram como uma de suas consequências a realocação de função de muitas professoras/es dentro da escola ou, na maioria dos casos, o remanejamento para outros órgãos vinculados ao governo estadual.

Ao ouvirmos essas pessoas se reportarem a outros tempos da escola, foi possível perceber o (res)sentimento por terem sido lesadas em seus direitos de fazerem suas próprias opções no espaço do trabalho. A indignação foi apontada na fala de uma professora da escola diante das mudanças introduzidas pela nova LDB e que conduziu à extinção dos cursos profissionalizantes que lá existiam:

Olhe... choca! Chocou e continua até o momento. Pra você ver, o curso que aqui era oferecido era considerado $O$ curso (...) além de ter a garantia de ter uma boa formação. Eram bem aceitos. Então como você vê, assim, uma imposição: de que esse curso vai deixar de existir [...]. (M, 2001, entrevista oral I)

A fala da professora, entrecortada pela emoção, misto de revolta e impotência, revela a ausência de autonomia da escola, dos docentes, na definição dos rumos da escola. As decisões e modos de funcionamento lhe chegam de cima para baixo. Não há 
uma esfera de negociação. Decretos, portarias, resoluções são sancionados, e exigidos o cumprimento desses atos normativos sem nem mesmo haver uma discussão mínima sobre o assunto. As modificações são preconizadas sem nenhuma informação, nenhuma discussão sobre as mesmas. Há, nos textos oficiais e nas falas de seus representantes, um discurso de melhoria da qualidade do ensino e da escola pública que não convenciam os/as professores/as.

No referente à extinção dos cursos profissionalizantes, por exemplo, a ideia da não absorção da mão de obra pelo mercado de trabalho, foi facilmente contraargumentada por uma professora, que vê a explicação dos textos oficiais, como desculpas $^{3}$ :

Aí começou com a desculpa de que, o mercado já não estava, mas isso não foi verdade! (...) Mas hoje o número de Clínicas existente na cidade... então, não justifica, o termo, 'mercado de trabalho'. Profissionais também não, porque já que os cursos eram todos da área de saúde, então tinha profissionais especializados, para o quê? Para manter o curso em si. (MC, 2001, entrevista oral II)

A princípio, parecem existir passividade e apatia por parte da comunidade escolar em torno das mudanças. Mas, ao olharmos mais detidamente a situação, observamos que houve movimentos de resistência em torno delas; mesmo que tímidos ou, talvez, não tão articulados, politicamente falando, ou, ainda, muito legalistas, em termos de estratégias de enfrentamento.

Tanto assim que, o grupo de professores se empenharam (sic) de todas as formas até elaborar projeto e ser encaminhado à Secretaria de Educação com justificativas, como uma forma de manter o curso. Mas, não houve resposta da Secretaria de Educação. Ou se houve resposta não foi aceito. Então, vários documentos foram feitos, até apoio da direção, que se prontificou, pra poder também intermediar [...]. (M2, 2001, entrevista oral IV)

De qualquer modo, a compreensão da imposição, do não posicionamento por parte de professores/as, da própria imobilidade presente na categoria, da fragilidade do

\footnotetext{
${ }^{3} \mathrm{O}$ curso profissionalizante oferecido era na área da saúde. O pessoal docente ouvido do extinto curso, afirmava existir na cidade demanda que justificaria a continuidade do curso.
} 
sindicato e que, através de uma ação mais organizada, poderiam (re)discutir as (im)posições, também se fazia presente:

Ele vem de cima pra baixo. Termina sendo uma imposição. Então é esse o negócio! (...) e a gente termina o quê? Aceitando! A gente é acomodada. Porque a gente aceita isso, passivamente. (...) nosso sindicato, não chama a gente pra ter essas discussões para discutir isso. Não chama! Porque dentro da própria escola, não dá! Então, dentro da nossa associação, convocar especialistas para dar depoimentos sobre isso. Você tá formando quem? (M2, 2001, entrevista oral IV)

Nesse quadro, a discussão em torno da concepção de currículo, do que tratou a reforma inaugurada pela nova LDB de 1996 e suas proposições em torno de temas e noções como interdisciplinaridade, competência e habilidade, agora trazidos como conceitos centrais nas propostas curriculares, pouco ou quase nunca foram, nem são, problematizados entre os/as docentes, nas reuniões de coordenação ou em outras reuniões, espaços de discussão e formação na escola.

O que ficou evidente foi a ausência de um debate no seio da comunidade escolar acerca das proposições e formulações que se apresentavam. Isso gerou mal-estar, confusão, descontentamento entre os profissionais da educação, principalmente por essas propostas acarretarem uma grande demanda sobre o trabalho do(a) docente, sem que isso viesse a significar melhoria efetiva de suas condições de realização, nem no sentido dos recursos materiais, estruturas física e pedagógico-formativa, nem no que tange à melhoria salarial.

O disposto nos artigos 35 e 36 da Lei $n^{\circ}$ 9.394/1996, em seu processo de materialização, requereu alteração curricular e isso significou, também, alteração na vida cotidiana do corpo profissional e estudantil nas e das escolas. Ora, substituir o caráter de formação profissionalizante pelo caráter de formação geral não pode ser pensado ou apropriado como simples alteração na terminologia, mas sim em alterações nas práticas cotidianas, na organização institucional e nos tempos da escola.

Fica posto que as proposições externas à escola, sem a participação efetiva e ativa da comunidade escolar e dos/as profissionais que nela atuam, referentes à chamada “melhoria da educação" não levam em conta a experiência, o cotidiano de professores/as 
e alunos/as. Na verdade, essas proposições demandaram uma ampliação do trabalho docente, materializado pelo incremento do número de instrumentos de avaliação, redução de carga horária das disciplinas, implicando no aumento da jornada de trabalho e na quantidade de turmas sob a responsabilidade de um mesmo docente. Ainda, associada a tudo isso, a ideia da expropriação do trabalho docente é muito intensa. Como sintetiza Enguita (1991, p. 48), “(...) O docente tem perdido progressivamente a capacidade de decidir qual será o resultado de seu trabalho, pois este já lhe chega previamente estabelecido em forma de disciplinas, horários, programas, normas, avaliação".

Tem-se nas propostas curriculares oficiais, formuladas no final dos anos de 1990, a definição dos princípios a serem seguidos pelos/as docentes sem que estes/as tivessem participado de sua produção. O que fica explícito é o caráter antidemocrático, autoritário e a ausência de autonomia do trabalho docente e da escola. Nesse sentido, quando refletia sobre os $\mathrm{PCN}$ e sobre a expropriação do trabalho docente nesse processo de reformulação curricular, Gentili (1996, p. 27) dizia que o Brasil foi no caminho da Educação Universal, mesmo que flexível. Para ele, os PCNs, por natureza, eram autoritários por sua mera existência.

O estado neoliberal é mínimo quando deve financiar a escola pública e máximo quando define de forma centralizada o conhecimento oficial que deve circular pelos estabelecimentos educacionais, quando estabelece mecanismos verticalizados e antidemocráticos de avaliação do sistema e quando retira autonomia pedagógica às instituições e aos atores coletivos da escola, entre eles, principalmente, aos professores. (GENTILI, 1996, p. 27)

Nessa perspectiva, Nacarato, Varani e Carvalho (1998) propunham que o fruto da tensão entre o que o sistema "burocrático" de ensino impõe e a degradação do trabalho dos/as docentes, eles e elas vivem o conflito entre, de um lado, sujeitar-se às regras impostas, buscando alternativas para viabilizar o trabalho, desconsiderando o que não Ihes pareça relevante, mediante a impossibilidade de dar conta de tudo, seja pelo tempo, seja pela lacuna da formação, o que por vezes leva esses profissionais a se sentirem cada vez mais desmotivados/as profissionalmente; de outro, esses mesmos docentes se veem, também, diante da situação de ter que se sujeitar à nova ordem, sem buscar ou 
vislumbrar alternativas; tentando cumprir o atributo do/a que seria um profissional competente e organizado/a nesse contexto marcados por relações de poder e controle.

\section{Atualizando o debate sobre o Ensino Médio: a Lei n 13.415/2017}

Em meados da segunda década do século XXI, a educação e a sociedade brasileira se defrontam com novas e profundas mudanças introduzidas na LDB de 1996, com a aprovação e sanção da Lei $n^{\circ}$ 13.415, de 16 de fevereiro de 2017, resultante da tramitação da Medida Provisória 746, de 22 de setembro de 2016. Novas mudanças, novos desenhos organizacionais, (nem tão) novas formas de pensar e organizar o currículo são anunciadas. Com efeito, esse novo arcabouço normativo trouxe em seu bojo elementos que impactaram, especialmente, nos mesmos artigos 35 e 36 que tratam do Ensino Médio, o que levou a se denominar essas alterações como uma "nova reforma do Ensino Médio", apesar de as alterações produzidas irem além dessa etapa da Educação Básica no lastro das ideias e princípios, e se sustentarem em formas de pensamento e de vida que se figuram entre aquelas que atentam contra as multiplicidades, e as diferenças - pilares do anseio democrático. Mas detenhamo-nos na chamada reforma do Ensino Médio.

Por um lado, o art. 35, que trata das finalidades e duração do Ensino Médio não sofreu nenhuma alteração em sua redação, mantendo, pois, a formulação original sistematizada em 1996. Mas, por outro lado, foi introduzido um novo artigo, que recebeu a numeração de art. 35-A, e produzidas significativas e profundas alterações no art. 36, que tratará da organização do currículo do Ensino Médio. Esses artigos, ao tratarem da Base Nacional Comum Curricular para o Ensino Médio (BNCC-EM), ainda que remetam à diretrizes a serem elaboradas pelo Conselho Nacional da Educação, já demarcam uma série de aspectos e elementos que deverão ser considerados na organização curricular dessa etapa da Educação Básica, portanto na formação continuada de professores e professoras.

Um primeiro aspecto se refere à divisão da BNCC-EM em quatro grandes áreas: linguagens e suas tecnologias; matemática e suas tecnologias; ciências da natureza e suas tecnologias e ciências humanas e sociais aplicadas. Ao lado dessa definição, as disciplinas de Sociologia e Filosofia deixaram de ser obrigatórias nessa etapa da Educação Básica, 
mas, ao mesmo tempo, ficou previsto que os estudos dos dois campos disciplinares, ao lado da Educação Física e das Artes, deverão estar contemplados na BNCC-EM. Ficou mantida a obrigatória da Língua Portuguesa e da Matemática nos três anos do Ensino Médio, assim como a obrigatoriedade do estudo da Língua Estrangeira (Inglês), sem especificar em quais anos, admitida uma segunda língua estrangeira, “em caráter optativo, preferencialmente o espanhol, de acordo com a disponibilidade de oferta, locais e horários definidos pelos sistemas de ensino" (Lei $n^{\circ}$ 9.394, § $4^{\circ}$, art. 35-A). Estaríamos aprofundando o olhar e pensamento colonizadores, uma questão para desdobramento em outro trabalho.

Quanto às diretrizes relativas à perspectiva de formação a serem desenvolvidas no currículo do Ensino Médio, o novo texto legal prevê que esses currículos “deverão considerar a formação integral do aluno, de maneira a adotar um trabalho voltado para a construção de seu projeto de vida e para sua formação nos aspectos físicos, cognitivos e socioemocionais" (Lei $\mathrm{n}^{\circ} \S 7^{\circ}$, art. 35-A). Essa é uma outra passagem que impõe desdobramentos para a formação continuada - ela pode ser constituída, por nossos campos de pesquisa, como possibilidade de desdobramento do que se coloca em curso no tempo presente, acerca da ideia de "[...] seu projeto de vida e para sua formação nos aspectos físicos, cognitivos e socioemocionais".

Ao lado dos aspectos relativos à organização curricular, a Lei $n^{\circ}$ 13.415/2017 introduziu, também, aspectos pertinentes à avaliação no e do Ensino Médio. Nesse sentido, destacam-se dois aspectos: o primeiro diz respeito ao fato de que caberá ao governo federal, a partir da BNCC-EM, estabelecer padrões de desempenho a serem alcançados pelas escolas e sistemas de ensino nessa etapa da Educação Básica.

Ainda sobre a avaliação, as alterações na LDB de 1996, resultantes dessa nova Lei em análise, preveem que "as formas de avaliação processual e formativa serão organizados nas redes de ensino por meio de atividades teóricas e práticas, provas orais e escritas, seminários, projetos e atividades on-line, de tal forma que ao final do ensino médio o educando demonstre: I - domínio dos princípios científicos e tecnológicos que presidem a produção moderna; II - conhecimento das formas contemporâneas de linguagem" ( $\left(8^{\circ}\right.$, art. 35-A). 
Outra mudança estruturante na organização do Ensino Médio produzida pelas novas bases introduzidas pela Lei $n^{\circ}$ 13.415/2017, diz respeito à previsão dos chamados itinerários formativos, a serem "organizados por meio da oferta de diferentes arranjos curriculares, conforme a relevância para o contexto local e a possibilidade dos sistemas de ensino" (art. 36 - grifos nossos).

São previstos cinco itinerários formativos: linguagens e suas tecnologias; matemática e suas tecnologias; ciências da natureza e suas tecnologias e ciências humanas e sociais aplicadas e, ainda, o itinerário relativo à formação técnica e profissional. A definição quanto à organização das áreas correspondentes a cada itinerário formativo, assim como às respectivas competências e habilidades, ficou designado para cada sistema de ensino fazê-lo. Do mesmo modo, caberá a esses sistemas de ensino definir quanto à possibilidade de o aluno poder cursar mais de um itinerário formativo, assim como a oferta do itinerário formativo com ênfase técnica e profissional. No caso desse último itinerário, está previsto, no $\S 6^{\circ}$ do art. 36 , que os sistemas de ensino poderão considerar as seguintes estratégias e formas de implementação em sua organização:

I - a inclusão de vivências práticas de trabalho no setor produtivo ou em ambientes de simulação, estabelecendo parcerias e fazendo uso, quando aplicável, de instrumentos estabelecidos pela legislação sobre aprendizagem profissional;

II - a possibilidade de concessão de certificados intermediários de qualificação para o trabalho, quando a formação for estruturada e organizada em etapas com terminalidade. É admitida, ainda, a possibilidade de esta formação técnica e profissional ser ofertada tanto na própria instituição de ensino quanto em parceria com outras instituições, porém, em ambos os casos, devendo ser previamente aprovada pelo Conselho Estadual de Educação e homologado pelo Secretário da respectiva Unidade Federativa.

As novas faces do Ensino Médio resultantes desses novos marcos regulatórios preveem, ainda, a possibilidade de firmar convênios com instituições de educação a distância com "notório reconhecimento" enquanto forma para atendimento dos novos desenhos curriculares e formativos que se delineiam para essa Etapa da Educação Básica, para os/as profissionais que nela atuam. 
Por último, mas sem esgotar todos os aspectos relativos aos novos contornos preconizados para o Ensino Médio no escopo da Lei $n^{\circ} 13.415 / 2017$, vale registrar as alterações previstas quanto às formas de sua organização e quanto à sua carga horária. No primeiro caso, passou a ser admitida a possibilidade dessa etapa da educação básica ser "organizada em módulos e adotar o sistema de créditos com terminalidade específica”, mantida a possibilidade de ser organizado "em séries anuais, períodos semestrais, ciclos, alternância regular de períodos de estudos, grupos não-seriados, com base na idade, na competência”. No segundo caso, ficou prevista a progressiva ampliação da carga horária mínima anual do Ensino Médio de oitocentas horas anuais para mil e quatrocentas horas anuais, sendo que a partir de março de 2022 deverá ser assegurada a duração de, pelo menos, mil horas anuais de carga horária.

Essas novas mudanças anunciadas para o Ensino Médio nos remetem, por um lado, a pensar seu sentido e lugar nas lutas de interesse e poder pela busca de determinadas formas de se compreender a formação da juventude (FERRETI; SILVA, 2017) e, por outro, as formas de se pensar a organização da escola e do currículo no campo educacional brasileiro (GONÇALVES, 2017). Há que se registrar, ainda, o caráter autoritário e instrumental dessa reforma (KUENZER, 2017; MOTTA; FRIGOTTO, 2017; SCHEIBE; SILVA, 2017), ao lado de sua vinculação com os interesses do mercado, tanto do mercado de trabalho quanto do mercado educacional, que a engendram.

A determinação de mudanças tão significativas na organização da escola e dos processos educativos definidos de forma açodada por meio da MP 476/2016, que em um intervalo de menos de quatro meses foi convertida na Lei 13.415/2017, evidenciam esse caráter. Por sua vez, a flexibilização e diversificação dos itinerários formativos, definidos nos novos marcos regulatórios, acabam por atender tanto aos interesses de setores e grupos econômicos hegemônicos na sociedade, quanto aspirações de segmentos no campo educativo, seja público ou privado, que tem nessa flexibilização um pilar importante para fazer com que a oferta do Ensino Médio ocorra conforme o contexto e a realidade em que ela se insere.

E todas essas reformas adentram à escola, daí que pensar essa escola e suas relações hoje parece ser bem mais do que simplesmente voltar o olhar para as relações estabelecidas aqui e agora, desconsiderando a ideia da interconexão entre passado e 
presente. Isso seria impossível, dada a temporalidade eminente marcada nas falas ouvidas nos espaços da escola. Há um processo intercambiante entre o que foi a escola e o que ela está sendo.

Para Sacristán (1996, p. 50), "as reformas são referentes atraentes para analisar os projetos políticos, econômicos e culturais daqueles que as propõem e do momento histórico no qual surgem". Portanto, considerar esse elemento é nos aproximar da produção da escola. Pois,

[...] as reformas representam uma oportunidade privilegiada para adquirir experiência política e social sobre como uma sociedade e os grupos no seu interior percebem e valoram os temas educacionais, podendo-se verificar que papel desempenha a educação na trama social. (SACRISTÁN, 1995, p. 55)

Essa análise nos fornece os elementos de constituição da escola, do seu projeto educativo e formativo, a quem está e esteve destinada e o porquê dessa destinação; evidencia as articulações entre as relações micro/macro do seu universo, pois, cria possibilidades de leitura do que se instaura como realidade e da sua dinâmica de produção do que se constitui como "real".

\section{Reformas educativas e currículo}

De outra parte, as mudanças apresentadas via proposição curricular instituem para aqueles/as aos quais se dirigem saberes e modos de ser, de fazer e de se comportar nos diferentes níveis institucionais. Dizem respeito a um certo entendimento de formação e do exercício docente. Os discursos trazidos pelas proposições vão sendo incorporados aos discursos e modos de vida dos diversos segmentos que compõem a escola.

As políticas curriculares autorizam certos grupos de especialistas, ao mesmo tempo que desautorizam outros. Elas fabricam os 'objetos epistemológicos' de que falam, por meio de um léxico próprio, de um jargão, que não deve ser visto apenas como uma moda, mas como um mecanismo altamente eficiente de instituição e de constituição do 'real' que supostamente the serve de referente. (...) A proposta curricular 
agora já transformada em currículo tem efeitos na sala de aula. (SILVA, 1999, p. 11)

As políticas curriculares, também, terminam apontando para a elaboração e escolha dos diversos textos que circulam nos espaços da escola, nos seus mais diversos setores. São as orientações contidas no que dizem, afirmam, indicam o texto curricular que geram, dinamizam as escolhas de outros textos que possam vir a circular (ou não) na escola. Assim, o currículo e suas reformas movimentam toda a cultura escolar e provocam efeitos na sala de aula. As funções professores/as e alunos/as e suas relações são ditas por essas políticas e reformas curriculares. O conhecimento que é considerado válido, as formas de verificação de sua aquisição, também são por elas definidos. Desse modo, deslocamentos de saberes, de procedimentos, inclusão e exclusão de indivíduos são aí operados (SILVA, 1999).

Por certo, o conceito currículo articula-se com outras noções como a de educação, poder, formação, escola e sociedade. Ao mesmo tempo em que se demonstra indignação quanto aos "pacotes" que chegam às escolas, à verticalidade das decisões, do fazer docente, a noção de educação também está carregada dessa 'exterioridade', verticalidade. Ou seja, o currículo é entendido como algo "que passa", "que deve ser aplicado". Assim, estabelece-se uma relação entre alguém que sabe, detém conhecimento, levando a outrem que não detém conhecimento, ou se o detém, "é restrito e contraditório". Nessa via de entendimento, as noções de educação, formação e poder se fazem presentes e são tomadas nessa mesma acepção. Em outras linhas, diríamos: as bases epistemológicas são as mesmas.

O currículo, então, aparece como outro conceito central para o entendimento de como o redirecionamento do ensino médio e as novas proposições curriculares, são vivenciadas no espaço da escola pelos/as professores/as, em seus processos formativos e também dos/as estudantes. O currículo, nessa perspectiva, deve ser tomado enquanto articulação de processos e práticas de controle e de poder. Tratando dessa articulação, Moreira e Silva, em 1995 (p. 28-30), já apontavam para a centralidade dessa noção na teorização educacional e curricular. Para eles, "o poder se manifesta nas relações sociais em que certos indivíduos ou grupos estão submetidos à vontade e ao arbítrio de outros". 
A ideia de prescrição está posta na história da produção do currículo. Goodson (1995), ao analisar o sentido etimológico do termo currículo, assinalou que o vínculo entre currículo e prescrição foi, pois, forjado desde muito cedo, e, com o passar do tempo, sobreviveu e se fortaleceu, e está a se fazer presente ainda nesta primeira metade do século XXI, de modo mais estranhado.

Partindo da ideia de multiplicidade da noção de currículo, é possível entender que as práticas, os fazeres e os dizeres das professoras e dos professores, como também de outros grupos, vão gerando uma dinâmica, externos ou não à comunidade escolar, que produzem exclusão, ordenação, distribuição de saberes, poderes e fazeres no espaço escolar. Em suma, o texto curricular, as políticas sociais invadem o espaço escolar através do currículo e este vai sendo apropriado, transformado, alterado, no correr dos dias e das trocas estabelecidas, nos mais variados espaços, lugares da escola e fora dela.

Assim, nas/pelas práticas cotidianas, sujeitos vão sendo constituídos no espaço escolar. Os atores e atrizes dessa escola vão utilizando suas lógicas e práticas, o que Garfinkel chamaria de etnométodos ${ }^{4}$, para a realização de suas atividades e estabelecimento de modos de vida em seu cotidiano escolar e extraescolar. Nesse sentido, o currículo é tomado numa perspectiva para além do conjunto de conteúdos e/ou disciplinas, e esse é o desafio a ser colocado em funcionamento em nossas práticas de formação. Passa a ser entendido como "modos de dizer e fazer" estruturantes da atividade educativa.

No reconhecimento dos dizeres e fazeres emergiram as preocupações, os procedimentos, os entendimentos daquilo a que a escola e o grupo de professoras, trazidos nas páginas iniciais deste trabalho, se dispunham, ou ainda, a que se propunham construir, formar. Nesse intuito, chamou-nos atenção a preocupação trazida pelas professoras com a formação das meninas e dos meninos. Ou seja, a crença da escola no que deviam meninas e meninos saberem, o que a escola deveria contemplar no processo formativo de seus estudantes, e, em seus próprios processos formativos. Nisso, reside a

\footnotetext{
${ }^{4}$ Etnométodos "são os métodos que os indivíduos utilizam para levar a termo as diferentes operações que realizam em sua vida cotidiana”. Os etnométodos são proposições da Etnometodologia que é uma postura em pesquisa, uma teoria do social que nada tem a ver com uma metodologia de pesquisa ou metodologia científica. Segundo Coulon, "esta foi uma expressão forjada por Harold Garfinkel, fundador da corrente e “inventor' da palavra". A esse respeito cf. COULON, Alain. Etnometodologia e Educação. Petrópolis: Vozes, 1995. p. 15-16. Ver também, GARFINKEL, H. Studies in Etnometodology. Cambridge: Polity Press, 1994, 288p.
} 
elaboração definida de mulheres e de homens, proposta por uma intenção educativa. Isso, também, conduziu-nos à ideia de vontade, de verdade abordada pelo filósofo francês Michel Foucault (1996). Para ele, um dos sistemas de exclusão utilizado, historicamente, em nossa sociedade:

Ora, essa vontade de verdade, como os outros sistemas de exclusão, apoia-se sobre um suporte institucional: é ao mesmo tempo reforçada e reconduzida por um todo compacto conjunto de práticas como a pedagogia, é claro, como o sistema dos livros, da edição, das bibliotecas, como a sociedade dos sábios outrora, os laboratórios hoje. Mas ela é também reconduzida, mais profundamente sem dúvida, pelo modo como o saber é aplicado em uma sociedade, como é valorizado, distribuído, repartido e de certo modo atribuído. (FOUCAULT, 1996, p. 17)

O currículo, nessa via de entendimento, reflete situações históricas, sociais e culturais, e funciona como um "regime de verdade". Nas conversas com as professoras nas escolas sobre suas práticas e suas experiências curriculares, as inquietações expostas giravam em torno de uma "crise" de desautorização dos profissionais da educação e essa crise permanece nos tempos que correm.

O currículo nunca é apenas um conjunto neutro de conhecimentos, que de algum modo aparece nos textos e nas salas de aula de uma nação. Ele é sempre parte de uma tradição seletiva, resultado da seleção de alguém, da visão de algum grupo acerca do que seja conhecimento legítimo. É produto das tensões, conflitos e concessões culturais, políticas e econômicas que organizam e desorganizam um povo. (APPLE, 1995, p. 59, grifo do autor)

Entender o currículo como Apple o fez, permitiu-nos romper com uma certa visão e posicionamento político-educativo que o colocou no lugar de isenção e neutralidade. Posicionamento esse vinculado a um modelo de racionalidade que tem guiado parte significativa da sociedade e da escola moderna.

É primordial para a leitura da educação e da formação docente entender, como nos afirma Silva (1995, p. 8-9) que “o processo de fabricação do currículo não é um processo lógico, mas um processo social, no qual convivem lado a lado com fatores lógicos, epistemológicos, intelectuais, determinantes sociais menos 'nobres' e menos 
'formais'(...)”. Esses determinantes sociais seriam, por exemplo, “interesses, rituais, conflitos simbólicos e culturais, necessidades de legitimação e de controle, propósitos de dominação dirigidos por fatores ligados à classe, à raça, ao gênero (...) (SILVA, 1995, p. 9)". Nesse sentido, como bem pontuou Silva, o currículo é constituído de

conhecimentos considerados socialmente válidos. Diante disso, a educação institucionalizada representa uma espécie de condensação do social em cima da qual os diferentes grupos sociais refletem e projetam suas visões e expectativas (...) o currículo acaba por expressar exatamente, entre outras coisas, a forma como certas questões são definidas, como 'problemas' sociais. (SILVA, 1999, p. 9)

Assim, a noção de currículo apresentada à escola, via órgãos oficiais de educação, é interessada e expressa uma noção de currículo datado e marcado historicamente, vinculado àquilo que determinados grupos produzem como sendo os "problemas sociais" de nossa sociedade neste momento. Assim, devem ser tratados e considerados pela escola e por aqueles e aquelas que nela vivem e dela participam.

\section{À guisa de conclusão: desafios à docência e à formação docente}

As noções de formação docente e docência não estão desarticuladas da ideia de currículo, e, como pano de fundo, se fazem presentes a noção de educação e de projeto de sociedade que, por e através destas, se deseja implementar. Tem-se, pois, dois conceitos articulados: com efeito, formação e docência são conceitos dotados de um caráter polissêmico e seus sentidos e significados resultam do caráter histórico e político ao qual estão vinculados e se produziram. Nessa perspectiva, concordando com Macedo (2000), "neste mundo tão etéreo, é preciso cultivar um certo ceticismo saudável, uma certa vigilância crítica em relação ao que está sendo proposto" como mudança (MACEDO, 2002, p. 254), e acrescentaríamos, ao que está sendo proposto como formação e como docência; ao que está por vir.

Essa vigilância nos faz perceber que, por vezes, o que se chama de mudança, efetivamente, não passa de um jogo discursivo para fazer alguns crerem que estas, de fato, estão se processando. Nos relatos encontrados nas vozes dos/das professoras 
diante das alterações provocadas pela LDB de 1996 no Ensino Médio, a ausência de uma fundamentação teórica mais consistente, em uma parte significativa da escola, em certa medida, explicava o movimento e a preocupação em dar conta do que lá chegara. Discutia-se e reclamava-se pela ausência de uma discussão anterior, mas não se levantara em momento algum a possibilidade de questionamento do que, naqueles textos, estavam postos. Há que se problematizar em que medida tal postura não se repete na atualidade frente às alterações provocadas pela Lei $n^{\circ}$ 13.415/2017 neste mesmo Ensino Médio.

Por vezes, a docência é entendida enquanto dom, virtude ou condição, ou, de outro modo, como apenas a realização do magistério, o ato de ministrar aulas. Saindo das teias dessas construções, a docência é apreendida como a atividade realizada por docentes, como "força de trabalho", realizada de acordo com uma forma de organização e condições determinadas. Também associada a essa dinâmica produtiva, focalizam-se a construção, significação e produção dos sentidos dos indivíduos a ela submetidos. Assim, a dimensão dos processos de subjetivação é, portanto, uma outra face dessa dinâmica que pode ser entendida como docência. Foi nessa perspectiva de condução de análise que Souza (1996) buscou compreender, a partir do cotidiano de professoras e de professores, os modos como estes/as vivenciam e representam o processo de trabalho docente, entendendo-o "como construção de experiências singulares, que pode[m] ser identificada[s] a partir dos valores, das trajetórias dos sujeitos que são interpretados pelos professores, dando-Ihes significados" (SOUZA, 1996, p. 18).

Ora, uma compreensão ampliada de docência nos conduz a perguntar sobre as possíveis razões para não vermos incluídos nos currículos e processos de formação inicial e continuada de professores e de professoras, em posição central e não periférica, discussões acerca das elaborações curriculares, da construção do conceito de currículo, das reformas educativas.

Oliveira e Nicolodi (2012) chamam atenção para o fato de que as reformas educativas realizadas no Ensino Médio desde meados dos anos de 1990 não vieram acompanhadas de sólidas políticas e processos de formação docente. Isso parece estar a acontecer quando adentramos às mudanças previstas para essa etapa da Educação Básica, a partir do que está posto pela Lei $n^{\circ} 13.415 / 2017$, na esteira do que foi possível 
constatar no estudo realizado, que considerou os processos de reformulação do Ensino Médio introduzidos a partir da Lei n 9.394/1996. As/os professoras/es deixavam, nas entrevistas realizadas, o entendimento de que a reforma ou adequação curricular fazia referência não só à função, ao papel do Ensino Médio mas, sobretudo, ao tipo e perfil de professor e professora requeridos. Nesse sentido, se problematizava, também, sobre qual formação docente a nova realidade requeria, sendo que tinham clareza que aquela formação que possuíam, na maioria dos casos, não era suficiente. E esta problematização se faz, ainda mais, urgente e necessária.

Aqui residem as bases da formação demandada, em especial, da formação continuada dos profissionais da educação. Uma formação que, para ser consequente e negar a barbárie, precisa problematizar os sentidos, significados e dimensões das reformas educativas e curriculares. Uma formação que coloque em questão os processos e práticas centralizados e centralizadores dessas reformas e que possibilite a interação, a troca de saberes, o compartilhar de experiências, em um ambiente orientado pelo diálogo permanente, pela crítica, pela reflexão coletiva, enfim, pelo espírito democrático em defesa de práticas democráticas.

\section{Referências}

APPLE, Michael W. Trabalho docente e textos: economia política das relações de classe e de gênero em educação. Porto Alegre: Artes Médicas, 1995.

BERTICELLI, Ireno Antonio. Currículo: tendências e filosofia. In: COSTA, Marisa Vorraber (Org.). $O$ currículo nos limiares do contemporâneo. 3. ed. Rio de Janeiro: DP\&A, 2001. p. 159-175.

ENGUITA, Mariano F. A ambiguidade da docência: entre o profissionalismo e a proletarização. Teoria e Educação, Porto Alegre, n. 4, p. 41-61, 1991.

ESPÓSITO, Vitória Helena Cunha. O que é isto, a escola? In: SERBINO, Raquel Volpato; LIMA GRANDE, Maria Aparecida Rodrigues de. A escola e seus alunos: o problema da diversidade cultural. São Paulo: Editora da Universidade Estadual Paulista, 1995. p. 115-120. (Seminários e debates). 
FERRETI, Celso João; SILVA, Monica Ribeiro da. Reforma do Ensino Médio no contexto da Medida Provisória n 746/2016: estado, currículo e disputas por hegemonia. Educação e Sociedade [online], Campinas-SP, v. 38, n. 139, p. 385-404, 2017. Disponível em: <http://dx.doi.org/ 10.1590/es0101-73302017176607>. Acesso em: 31 mar. 2019.

FOUCAULT, Michel. A ordem do discurso. 3. ed. São Paulo: Loyola, 1996 (Leituras filosóficas).

GENTILLI, Pablo. Neoliberalismo e educação: manual do usuário. In: SILVA, Tomaz Tadeu da; GENTILI, Pablo (Org.). Escola S.A. : quem ganha e quem perde no mercado educacional do neoliberalismo. Brasília: CNTE, 1996, p. 9-49.

GONÇALVES, Suzane da Rocha Vieira. Interesses mercadológicos e o "novo" ensino médio. Revista Retratos da Escola, Brasília, v. 11, n. 20, p. 131-145, jan./jun. 2017. Disponível em: <www.retratosdaescola.emnuvens.com.br/rde/article/view/753>. Acesso em: 25 mar. de 2019 .

GOODSON, Ivor F. Currículo: teoria e história. Trad. Hamilton Francischetti. Petrópolis, Rio de Janeiro: Vozes, 1995.

KUENZER, Acacia Zeneida. Trabalho e escola: a flexibilização do Ensino Médio no contexto do regime de acumulação flexível. Educação e Sociedade [online], Campinas-SP, v. 38, n. 139, p. 331-354, 2017. Disponível em: <http://dx.doi.org/10.1590/es010173302017177723>. Acesso em: 31 mar. de 2019.

M, Fulana de. Entrevista I. [abr. 2001]. Entrevistador: Elenita Pinheiro de Queiroz Silva. Feira de Santana-BA, 2001. 1 cassete (60 min.).

M1, Fulana de. Entrevista III. [abr. 2001]. Entrevistador: Elenita Pinheiro de Queiroz Silva. Feira de Santana-BA, 2001. 1 cassete (60 min.).

M2, Fulana de. Entrevista IV. [abr. 2001]. Entrevistador: Elenita Pinheiro de Queiroz Silva. Feira de Santana-BA, 2001. 1 cassete (60 min.).

MACEDO, Roberto Sidnei. A etnopesquisa crítica e multirreferencial nas ciências humanas e na educação. 1 ed. Salvador, EDUFBA, 2002.

MC, Fulana de. Entrevista II. [abr. 2001]. Entrevistador: Elenita Pinheiro de Queiroz Silva. Feira de Santana-BA, 2001. 1 cassete (80 min.).

MOREIRA, Antonio Flávio e SILVA, Tomaz T. da (Org.). Currículo, Cultura e Sociedade. 2.ed. São Paulo: Cortez, 1995.

MOTTA, Vânia Cardoso da; FRIGOTTO, Gaudêncio. Por que a urgência da reforma do Ensino Médio? Medida Provisória Nº 746/2016 (Lei N 13.415/2017). Educação e Sociedade [online], Campinas-SP, v. 38, n.139, p. 355-372, 2017. Disponível em: <http://dx.doi.org/ 10.1590/es0101-73302017176606>. Acesso em: 28 mar. 2019. 
NACARATO, Adair Mendes; VARANI, Adriana; CARVALHO, Valéria de. O cotidiano do trabalho docente: palco, bastidores e trabalho invisível... abrindo as cortinas. In: GERALDI, Corinta Maria Grisolia; FIORENTINI, Dario; PEREIRA, Elisabete Monteiro de Aguiar.

Cartografias do trabalho docente: professor(a)-pesquisador(a). Campinas, São Paulo: Mercado das letras, 1998. p. 73-104.

OLIVEIRA, João Ferreira de e NICOLODI, Elaine. Outro Ensino Médio é possível? reforma e políticas de formação e valorização docente em questão. Ensino Em Re-Vista. Uberlândia, v. 19, n. 01, p. 131-144, jan./jun. 2012. Disponível em :

<http://www.seer.ufu.br/index.php/emrevista/article/view/14909/8480>. Acesso em: 22 mar. de 2019.

SACRISTÁN, José Gimeno. Reformas educacionais: utopia, retórica e prática. In: SILVA, Tomaz Tadeu da e GENTILI, Pablo (Org.) Escola S.A.: quem ganha e quem perde no mercado educacional do neoliberalismo. Brasília: CNTE, 1996, p. 50-74.

SILVA, Tomaz Tadeu da. Documentos de identidade: uma introdução às teorias do currículo. Belo Horizonte: autêntica, 1999. 152p.

SCHEIBE, Leda; SILVA, Monica Ribeiro da. Reforma do ensino médio: pragmatismo e lógica mercantil. Revista Retratos da Escola, Brasília, v. 11, n. 20, p. 19-31, jan./jun. 2017. Disponível em: <retratosdaescola.emnuvens.com.br/rde/article/view/721>. Acesso em: 25 mar. de 2019.

SOUZA, Aparecida Neri de. Sou professor, sim senhor! Campinas, São Paulo: Papirus, 1996. 